\title{
REVERSE LOGISTICS AS A TREND OF XXI CENTURY - STATE OF ART
}

\author{
Monika KOSACKA-OLEJNIK, Karolina WERNER-LEWANDOWSKA \\ Poznan Univeristy of Technology
}

\begin{abstract}
:
On the basis of legal, environmental, social, and economic factors, reverse logistics and closed-loop supply chain issues have attracted attention among both academia and practitioners. A growing number of publications is an expression of reverse logistics trend in the literature which has been lasted for around 40 years. Hence, a comprehensive literature review of recent and state-of-the-art papers is vessential to draw a framework of the past, and to support researchers in their works by indicating journals or adequate references. The aim of this paper was to prepare appropriate literature review procedure and following it to review all papers whose main topis was reverse logistics. The papers were analyzed and categorized to construct a useful foundation of past research with respect to the scale of number of research on reverse logistics, considering stages of reverse logistics development, targeted journals, main research centres and leading countries. Moreover there were reccommended the most valuable papers as references.
\end{abstract}

Key words: literature review, reverse logistics, state of art

\section{INTRODUCTION}

The reverse logistics is a young concept, that has been of particular interest to the academic community as well as industry, since $1982^{1}$. Currently, it may be observed growing interest of the concept, owing to the fact that "linear economy" model of "taking, making, consuming, disposing", has become out of date. The significance of the reverse logistics activities has been increased as there have been many reasons for products' returns what was described in details by Gandolfo and Sbrana in [6].

The reverse logistics creates together with the sourcing, production and distribution, the company's logistics system which has been reflected in the worldwide relevant journals on production, operations management and logistics. However, it took a while for reverse logistics in being widely defined, there have been identified a few issues requiring explaination. Firstly, the definition of the concept including the process architecture of the reverse logistics subsystem. It was claimed that, there are few definitions of reverse logistics proposed by: Dowlatshahi [4], Rogers and Tibben-Lembke [16], Stock [19], which are commonly accepted. In the paper there was adopted the proposal of the European Working Group on Reverse Logistics, REVLOG that has defined reverse logistics as the process of planning, implementing and controlling backward flows of raw materials, in process inventory, packaging and finished goods, from a manufacturing, distribution or use point, to a point of recovery or point of proper disposal [3]. In the presented definition, the emphasis was put into: processess of reverse logistics and material flow between particular objects (actors).

With reference to previous studies on reverse logistics, it was stated that the reverse logistics term may cause confusion with issues that are related to it e. g. industrial ecology, green supply chains, waste management, etc. The presented research is focused on reverse logistics. Considering the fact, that reverse logistics is mature concept, the main research topics in the filed of reverse logistics and major research centers carrying out research on that topic should be indentified.

The paper's objective was to provide an overview on the current state of art on reverse logistics. In order to achieve specified main objective, there were determined the following partial objectives:

- O1: Review methodology development;

- 02: Literature review analysis;

- O3: Reporting results of conducted research.

In view of this interest, there was proposed to analyse the main characteristics of the most valuable studies in order to evaluate, what have been known in the area of reverse logistics.

The paper was structured as follows: firstly, the review methodology was desribed. Following review methodology in the Section 2, there was made a literature review on the reverse logistics within the range, as specified in research questions. In this section there were outlined the main findings of conducted research. In the summary, there were presented conclusions and final reflections. 


\section{REVIEW METHODOLOGY}

In the paper there was adopted an approach for analysis of the literature determined by Kitchenham [9]. As a result, there was planned research consisted of three stages, presented in the Fig. 1.

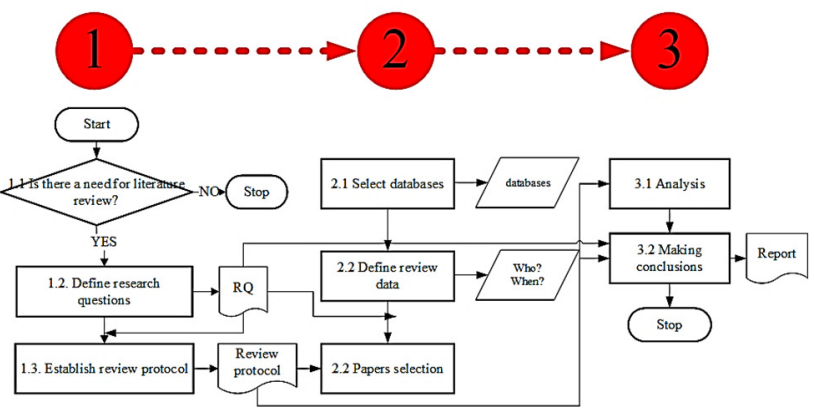

Fig. 1 Review methodology

According to Fig. 1, in the first stage, the literature review is being planned. At that stage there should be identified a need for literature review as well as research questions should be determined to propose the route to be taken in the research. The last important issue at this stage is a review protocol, which contains selection criteria, to determine: works included in the review, the data sources, search strategy and the search strings. Review protocol affects the second stage of the procedure, owing to the fact that there is made papers' selection according to the guidelines in the review protocol with the use of selected databases. The initial search results should be analyzed with respect to their relevancy applying the inclusion/exclusion criteria (they may be specified or not).

Moreover, relevant studies which fulfill selected criteria should answer the research questions. Finally, based on the extracted data, the encountered studies should be analyzed with respect to identified research questions, and results should be synthesized in order to prepare conclusions in a form of a report. To sum up, it was claimed that partial objective 01 was achieved and prepared procedure (Fig. 1) was used in order to make a literature review on the reverse logistics in Section 2.

\section{LITERATURE REVIEW ON THE REVERSE LOGISTICS}

\section{Stage 1: Planning}

Initally, according to procedure in the Fig. 1, the literature review should be preceded by justification for that activity. In authors' opinion, the need for a systematic review on the reverse logistics arose from the requirement of researchers to summarise all existing information about that phenomenon in a thorough and unbiased manner. It was made in order to draw more general conclusions about reverse logistics, than it was possible from individual studies. It was also treated as a prelude to further research activities on reverse logistics maturity model development.

However, there have been idenftified some literature reviews on reverse logistics, there is lack of comprehensive approach which would answer the research questions explained in the Table 1.
Table 1

Research questions in the conducted literature research

\begin{tabular}{ccc}
\hline ID & $\begin{array}{c}\text { Research } \\
\text { question }\end{array}$ & Description \\
\hline RQ1 & $\begin{array}{c}\text { Is reverse } \\
\text { logistics } \\
\text { a subject } \\
\text { of research? }\end{array}$ & $\begin{array}{c}\text { Determination the level } \\
\text { of interest of the reverse } \\
\text { Logistics in scientific journals } \\
\text { including diversification of the: } \\
\text { publication time, country, } \\
\end{array}$ \\
& journal type.
\end{tabular}

Where

to publish

RQ2

papers about

reverse

logistics issues?

What are the

RQ3

most valuable

papers on reverse logistics?

Identification scientific journals oriented on reverse logistics.

Identification of the most valuable publication according to the number of citations.

The objective of this review was to elicit the state of art on reverse logistics. In this respect, it was aimed to obtain an overview on the existing papers on reverse logistics. In authors opinion, reverse logistics term requires verification from the perspective of the level of its exploration in the literature, what was expressed in the RQ1. In the RQ2 it was acknowledged that there is lack of guidelines related to process of journals selection, for publishing works on reverse logistics issues.

Finally, there was identified a need to find the most valuable works on reverse logistics to reccommend their use as reference for future research.

In order to answer research questions presented in the Table 1, there was determined the review protocol (Table 2).

According to data presented in the Table 2, a systematic search began with the identification of keywords and their synonyms. They were defined as a result of discussion within the review team consisted of authors of the paper. Using the main keywords (reverse logistics) and their synonyms with $O R$ Boolean operator between keywords, the following search string was defined: Title: "reverse logistics" OR "aftermarket logistics" $O R$ „retrogistics” $O R$ "aftermarket supply chain".

The search was limited to works in English with no time restrictions and no limits according to paper type. The English language was chosen, since it has the largest number of publications and hence more likely to offer essential works on the reverse logistics topic.

Authors recommended to use different inclusion criteria with respect to research questions $R Q$, in order to answer them properly and to limit number of papers. However, this search string did not guarantee returning only papers focused on the research topic, forcing the creation of inclusion criteria, excluding any work that did not address the issue of reverse logistics within the industrial context, what affected answering all research questions. 
Table 2

Review protocol

\begin{tabular}{|c|c|c|c|}
\hline Item & \multicolumn{3}{|c|}{ Description } \\
\hline Key words & $\begin{array}{l}\text { Core con- } \\
\text { cept } \\
\text { Reverse } \\
\text { logistics }\end{array}$ & $\begin{array}{l}\text { Aftermarket Logistics, Retrogistics, } \\
\text { Aftermarket Supply Chain }\end{array}$ & Synonyms ${ }^{2}$ \\
\hline $\begin{array}{l}\text { Boolean } \\
\text { operators }\end{array}$ & \multicolumn{3}{|c|}{ OR between keywords + synonyms } \\
\hline $\begin{array}{l}\text { Search } \\
\text { fields }\end{array}$ & \multicolumn{3}{|c|}{ Publication title } \\
\hline $\begin{array}{l}\text { Time win- } \\
\text { dow }\end{array}$ & \multicolumn{3}{|l|}{ No limit } \\
\hline Language & \multicolumn{3}{|l|}{ English } \\
\hline Paper type & \multicolumn{3}{|l|}{ No limit } \\
\hline \multirow{4}{*}{$\begin{array}{l}\text { Inclusion } \\
\text { criteria }\end{array}$} & \multicolumn{2}{|l|}{ Criterion } & $\mathrm{RQ}$ \\
\hline & \multicolumn{2}{|c|}{$\begin{array}{l}\text { Major paper's topic is reverse logistics } \\
\text { within the industrial context }\end{array}$} & $\begin{array}{l}\text { RQ1- } \\
\text { RQ3 }\end{array}$ \\
\hline & \multicolumn{2}{|c|}{$\begin{array}{l}\text { Top } 10 \text { worldwide journals with the hi- } \\
\text { ghest values of impact factor }\end{array}$} & RQ2 \\
\hline & \multicolumn{2}{|c|}{$\begin{array}{l}\text { Top } 10 \text { most frequently worldwide cited } \\
\text { papers }\end{array}$} & RQ3 \\
\hline
\end{tabular}

\section{Stage 2: Collection \& Selection}

Two online databases with the highest coverage for the research topic in authors' opinion were selected for the second stage of research (Fig. 1): Web of Science and SCOPUS. Keywords presented in the Table 2 were used in the search string calibrated and adapted in conformance with the specific syntax of each of the data sources. All searches were performed on 12 May 2018 by authors of the paper. Although there is a striking similarity between the search engines of the databases used, subtle differences made it necessary to change the search string to adapt it into each of the mechanisms. Table 3 shows the final search string used in each of the databases with the information about number of results.

Table 3

Search strings used in databases utylized in the research

\begin{tabular}{|c|c|c|}
\hline $\begin{array}{l}\text { Data- } \\
\text { base }\end{array}$ & $\begin{array}{l}\text { Application of search string } \\
\text { in database }\end{array}$ & $\begin{array}{l}\text { Number } \\
\text { of results }\end{array}$ \\
\hline SCOPUS & $\begin{array}{l}\text { (TITLE ("Aftermarket Supply Chain") OR } \\
\text { TITLE ("reverse logistics") OR TITLE } \\
\text { ("retrologistics") OR TITLE ("Aftermar- } \\
\text { ket Logistics")) AND (LIMIT-TO (LAN- } \\
\text { GUAGE, "English")) }\end{array}$ & 1312 \\
\hline $\begin{array}{l}\text { Web } \\
\text { of } \\
\text { Science }\end{array}$ & $\begin{array}{l}\text { (((TITLE: ("reverse logistics") OR TITLE: } \\
\text { (retrognostics)) OR TITLE: ("Aftermar- } \\
\text { ket Logistics")) OR (TITLE: ("Aftermar- } \\
\text { ket Supply Chain") AND LANGUAGE: } \\
\text { (English))) }\end{array}$ & 995 \\
\hline
\end{tabular}

After submitting the search string in the databases (Table $3)$, there was obtained a considereble number of results, what justifies that reverse logitics has been a relevant issue in the literature.

\section{Stage 3: Analysis \& Conclusions}

In the analysis phase, papers were considered according to: the source, country, research institution and organized by year of publication. This form of grouping was helpful in order to answer the RQ1 and to extract important information regarding the research trends in the study area.

\section{Publication Years}

Annual distribution of number of papers included in WoS (grey curve) and SCOPUS (black curve) databases is presented in the Fig. 2.

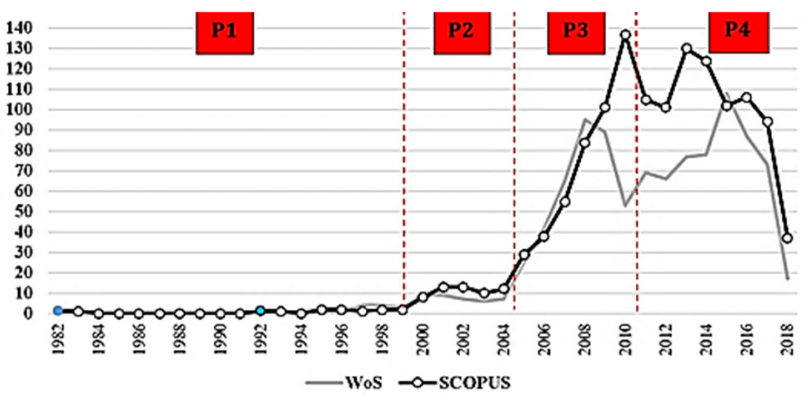

Fig. 2 Papers organized by the year of the publication in SCOPUS and WoS databases

According to chart presented in the Fig. 2, the papers were published from 1982 in SCOPUS [1] and from 1992 in WoS [2] onwards. With reference to the diagram, authors determined four phases of literature on the reverse logistics development (P1-P4), presented in the Table 4.

Table 4

Stages of reverse logistics development

\begin{tabular}{|c|c|c|c|c|}
\hline \multirow[t]{2}{*}{ Id } & \multirow[t]{2}{*}{ Phase } & \multirow{2}{*}{$\begin{array}{l}\text { Period of } \\
\text { time }\end{array}$} & \multicolumn{2}{|c|}{$\begin{array}{c}\text { Total number } \\
\text { of papers }\end{array}$} \\
\hline & & & WoS & SCOPUS \\
\hline P1 & Initial & ....-1999 & 13 & 11 \\
\hline P2 & Introduction & $2000-2004$ & 38 & 56 \\
\hline P3 & Growth & $2005-2010$ & 369 & 444 \\
\hline P4 & Maturity & $2011-\ldots .$. & 575 & 799 \\
\hline
\end{tabular}

With reference to data presented in the Table 4 and Fig. 2 , it was stated that till 1999, there was publiced very limited number of works on reverse logistics.

The concept was fresh and initially recognized. A small intermittent peak appeard in 2001 when more than 10 papers were published in SCOPUS and WoS, before dropping in 2004. It was Introduction phase, where there were taken efforts on more than general issues, because the level of knowledge was higher. In the growth phase, from 2005, the number of papers was considerably increasing reaching a peak in 2010, when there were 137 works in SCOPUS database. However, there were differences in number of papers in compared databases, the trends were quite similar. In the last stage, number of works fluctuated between 90-130 in SCOPUS and between 50-110 in WoS. There was a clearly defined pattern, that the numer of papers have increased considerably in last few years, owing to the fact that there was a growing interest of research on reverse logistics topic. It may be caused by increasing awareness of resources limitations. People are more familiar with the reverse logistics, but there has been still perceived necessity of conducting research in mentioned 
area, as a feature of the maturity stage is maintaining a high number of publications in the specific research area.

\section{Country and organizations - enhanced}

The identified papers were developed by researches from various countries (Table 5), representing many organizations.

According to data presented in the Table 5, almost $90 \%$ of all papers from each of considered databesases, where prepared by reserachers from top 15 countries, however the most productive countries have been: China, USA and India. More than half of all works on reverse logistics have been so far made by researchers from mentioned countries. It is interesting, that China, which is low-developed country in the aspect of sustainability policy realization, has become a source of around $30-40 \%$ of works on reverse logistics. It was assumed, that China has been a leading country in the research on reverse logistics, what may convince to find an important research centres and universities in China. Taking into consideration information about organizations, there have been identified top 3 centres including: Syddansk Universitet from Dannmark, Indian Institute of Technology Delhi in India and Wuhan University of Technology from China.

Table 5 Papers organized by the country of the publication - top 15 countries

\begin{tabular}{|c|c|c|c|c|c|c|c|}
\hline \multirow[b]{2}{*}{ Place } & \multirow[b]{2}{*}{ Country } & & & & & & \\
\hline & & SCOPUS & $\begin{array}{c}\% \\
\text { share }\end{array}$ & Top 3 & wos & $\begin{array}{c}\% \\
\text { share }\end{array}$ & Top 3 \\
\hline 1 & China & 414 & 31.55 & & 406 & 40.80 & \\
\hline 2 & United States & 151 & 11.51 & $52.8 \%$ & 108 & 10.85 & $58.1 \%$ \\
\hline 3 & India & 128 & 9.76 & & 64 & 6.43 & \\
\hline 4 & Brazil & 70 & 5.34 & & 51 & 5.13 & \\
\hline 5 & Iran & 56 & 4.27 & & 41 & 4.12 & \\
\hline 6 & Taiwan & 46 & 3.51 & & 29 & 2.91 & \\
\hline 7 & $\begin{array}{l}\text { United } \\
\text { Kingdom }\end{array}$ & 44 & 3.35 & & 30 & 3.02 & \\
\hline 8 & Canada & 39 & 2.97 & & 26 & 2.61 & \\
\hline 9 & Turkey & 34 & 2.59 & & 30 & 3.02 & \\
\hline 10 & Malaysia & 32 & 2.44 & & 19 & 1.91 & \\
\hline 11 & Spain & 32 & 2.44 & & 23 & 2.31 & \\
\hline 12 & Denmark & 31 & 2.36 & & 19 & 1.91 & \\
\hline 13 & Germany & 30 & 2.29 & & 18 & 1.81 & \\
\hline 14 & South Korea & 29 & 2.21 & & 16 & 1.61 & \\
\hline 15 & France & 27 & 2.06 & & 18 & 1.81 & \\
\hline \multicolumn{2}{|c|}{$\begin{array}{c}\text { Total share of all } 15 \\
\text { countries }\end{array}$} & \multicolumn{2}{|c|}{$88.6 \%$} & \multicolumn{3}{|c|}{$85.1 \%$} & \\
\hline
\end{tabular}

In the case of all mentioned organizations, more than $5 \%$ of all papers within considered databases, were prepared by researchers representing those univeristies. The presented data may be useful for cooperation in the case of research on the reverse logistics. What is more, it may be also useful if someone considers internship or future research work on reverse logistics.

\section{Targeted journals}

To comprehend the multi perspective view of the concept, papers identified after application search strings (Table 3 ) were selected from various scientific journals. The vast majority of papers were journal papers or conference proceedings. According to statistics, more than $98 \%$ in WoS and more than $94 \%$ in SCOPUS were articles or proceedings papers. Consequently, it was stated, that reverse logistics has become a subject of papers in scientific journals, as well as it has been a topic on many conferences. As a result of analysis of sources, it was stated that there was a significant dispersion of journals, where papers were published. In WoS there were identified 500 various journals and in SCOPUS there were identified 92 journals. Considering the fact, that among significant number of journals, only $3 \%$ of all sources in WoS and $14 \%$ sources in SCOPUS had 10 and more publications in the analyzed period of time, there should be taken into consideration to publish paper in one of the most widely chosen journal, according to staticstics presented in the Table 6.

Table 6

List of journals

\begin{tabular}{|c|c|c|c|c|}
\hline \multirow[t]{2}{*}{ Journal } & \multirow{2}{*}{ ڤ̊ } & \multirow{2}{*}{$\begin{array}{l}\text { ֻ } \\
\text { ర్ర }\end{array}$} & \multicolumn{2}{|c|}{$\begin{array}{l}\text { Impact } \\
\text { factor }\end{array}$} \\
\hline & & & (2016) & 5 year \\
\hline $\begin{array}{l}\text { International Journal of Logistics Sys- } \\
\text { tems And Management }\end{array}$ & $x$ & 31 & & \\
\hline Advanced Materials Research ${ }^{3}$ & 22 & 28 & & \\
\hline $\begin{array}{l}\text { International Journal of Production Eco- } \\
\text { nomics }\end{array}$ & 25 & 24 & 3.493 & 4.052 \\
\hline $\begin{array}{l}\text { International Journal of Production Re- } \\
\text { search }\end{array}$ & 24 & 24 & 2.325 & 2.388 \\
\hline Applied Mechanics and Materials ${ }^{6}$ & 13 & 23 & & \\
\hline Journal of Cleaner Production & 21 & 23 & 5.715 & 6.207 \\
\hline $\begin{array}{l}\text { International Journal of Physical Distri- } \\
\text { bution And Logistics Management }\end{array}$ & 12 & 22 & 2.577 & 3.98 \\
\hline Resources Conservation and Recycling & 21 & 22 & 3.313 & 4.141 \\
\hline Computers and Industrial Engineering & 15 & 15 & 2.623 & 2.859 \\
\hline $\begin{array}{l}\text { International Journal of Logistics Mana- } \\
\text { gement }\end{array}$ & 11 & 15 & 1.61 & 2.061 \\
\hline $\begin{array}{l}\text { International Journal of Advanced Ma- } \\
\text { nufacturing Technology }\end{array}$ & 12 & 13 & 2.209 & 2.298 \\
\hline $\begin{array}{l}\text { IEEE International Symposium on Elec- } \\
\text { tronics and the Environment }{ }^{6}\end{array}$ & 10 & 11 & & \\
\hline $\begin{array}{l}\text { European Journal of Operational Rese- } \\
\text { arch }\end{array}$ & 9 & 10 & 3.297 & 3.582 \\
\hline International Conference on Industrial & & & & \\
\hline $\begin{array}{l}\text { Engineering and Engineering Manage- } \\
\text { ment IEEM }{ }^{6}\end{array}$ & 21 & $x$ & & \\
\hline International Conference on Wireless & & & & \\
\hline $\begin{array}{l}\text { Communications Networking } \\
\text { and Mobile Computing } 6\end{array}$ & 11 & $x$ & & \\
\hline
\end{tabular}

With reference to data presented in the Table 6 , there were included journals which have had so far at least 10 publications, in both databases used in this paper. Vast majority of all journals were included in SCOPUS and WoS together, except the International Journal of Logistics Systems and Management available in SCOPUS database. In order to recommend journals for publishing works on reverse logistics, there have been used information from InCites Journal Citation Reports about impact factor from 2016 and average impact factor from 5 years. 
Considering data presented in the Table 6, it was recommended to publish works in top five journals in the following order: Journal of Cleaner Production, European Journal of Operational Research, International Journal of Production Economics, Resources Conservation and Recycling, International Journal of Physical Distribution and Logistics Management. These actions will ensure in authors' opinion, the best results in the citation and they will provide the highest value of work. As a result, there was obtained answer for RQ2. Moreover, foregoing considerations about: publication years, countries and organizations enhanced, targeted journals proved that RQ1 was solved.

In order to answer the RQ3, there were selected 10 most frequently cited works (top 10 citations in both databases used in the research), which have been cited till 2018. The above research results were presented in the Table 7 .

In order to recommend other researchers some valuable publications, there was made a citation report presented in the Table 7. With reference to data included into the Table 7, the most frequently cited work has been paper prepared by Fleischmann et al. [5] which was developed in the initial stage of research on reverse logistics according to Table 4. Number of citations of the mentioned study has been so far at least three times more than second publication, what confirms timeliness of issues presented in the first paper. The list of top 10 most cited articles is the same in the case of both databases used in the research, what confirms that selected papers have become valuable sources of information during preparation paper on reverse logistics issue. In the most frequently cited papers there were identified works on the following issues: state of art on the reverse logistics, modelling network for reverse logistics, theory of reverse logistics,

List of the 10 most cited articles in the Web of Science and SCOPUS WoS SCOPUS

Title Authors Ref Year Phase Number of citations

Quantitative models for reverse logistics: A review

Reverse logistics and closed-loop supply chain: A comprehensive review to explore the future

Developing a theory of reverse logistics

An optimization model for the design of a capacitated multiproduct reverse logistics network with uncertainty

Analysis of interactions among the barriers of reverse logistics

Network design for reverse logistics

A genetic algorithm-based heuristic for the dynamic integrated forward/reverse logistics network for 3PLs

Analyzing alternatives in reverse logistics for end-of-life computers: ANP and balanced scorecard approach

A genetic algorithm approach to developing the multi-echelon reverse logistics network for product returns

Perspectives in reverse logistics: A review practical application of reverse logistics on the basis of case studies. If there is prepared paper on one of the mentioned study, the paper from the list presented in the Table 7 should be used as a reference.

In authors' opinion, there should have been used always as reference a valuable source according to those, from citation report, but also timeliness publications. The most up-to-date work from the Table 7, was developed in 2015 [7]. Considering the data presented in the Table 3, there should be noticed, that the most frequently cited works were from years 2005-2010 (phase 3). Moreover, according to analysis of works cited 100 and more Times, in both databases ${ }^{4}$, it was confirmed, that more than $70 \%$ in WoS and around $60 \%$ in SCOPUS were publications highly cited and developed in the phase 3.

As a result, it was claimed, that researchers do not use so frequently references after 2011. It requires much time to develop so valuable work as paper of Fleischmann et al. [5]. With respect to presented information, authors recommend to use more actual references created after 2011.

\section{SUMMARY}

This article was authors' own attempt to synthetically present the state-of-the-art knowledge about the reverse Logistics. It was made with specially designed procedure of making the literature review, according to objective 01 . Considering the guidelines presented in the Fig. 1, there was made an analysis of papers on reverse logistics, which includes various aspects of analysis: number of papers, leading countries and research centres, targeted journals and papers valuable as a source of information.
Fleischmann, M; BloemhofRuwaard, JM; Dekker, R; van der Laan, E; vanNu- [5] $\begin{array}{lllll}1997 & \text { P1 } & 866 & 1119\end{array}$ nen, JAEE; Van Wassenhove, LN

Govindan, K., Soleimani, H., \& Kannan, D.

[7] $2015 \quad$ P4 $\quad 255 \quad 323$

Dowlatshahi, S

[3] $\begin{array}{llll}2000 & \text { P2 } & 251 & 341\end{array}$

Salema, M. I. G., Barbosa-Povoa, A. P., \& Novais, A. Q.

[17] $2007 \quad$ P3 $246 \quad 304$

Ravi, V; Shankar, R

[14] $2005 \quad$ P3 $226 \quad 341$

Srivastava, Samir K.

[18] $2008 \quad$ P3 $207 \quad 281$

Ko, Hyun Jeung; Evans, Gerald W.

[10] $2007 \quad$ P3 $201 \quad 273$

Ravi, V; Shankar, R; Tiwari, MK

[15] $2005 \quad$ P3 $201 \quad 282$

Min, H; Ko, HJ; Ko,CS

[12] 2006 P3 $183 \quad 247$

Pokharel, S., Mutha,A.

[13] $2009 \quad$ P3 169

226

\footnotetext{
${ }^{4}$ Total number of works cited 100 and more Times in WoS was 29 papers, in SCOPUS - 54 papers.
} 
There have not been identified work which would included presented issues, what may be seen as an evidence of research novelity. The essential results include guidelines for researchers: where to publish and what paper to cite? Effects of the analysis of the literature on reverse logistics were presented in the Section 3, what proves achieving objective 02 . What is more, it was stated that prepared paper became a report of conducted research, what is eqal with achieving goal 03. Moreover, there were identified stages literature on reverse logistics development. Currently, publications on reverse logistics represent maturity stage, what results in decreasing number of papers. However, the number of works is declining, while their value is rising.

The paper presents partial results of the research on the reverse logistics. Future research directions include extended literature research, in order to prepare framework for development a maturity model for reverse logistics.

\section{ACKNOWLEDGEMENTS}

This paper refers to the research conducted under Statutory activity, financed by MNiSW/Poznan University of Technology, project: Research on reverse logistics maturity of enterprise (Project ID: 503227/11/140/ DSMK/4152).

\section{REFERENCES}

[1] Jr. J.H. Barnes. „Recycling: A problem in reverse logistics”. Journal of Macromarketing, 2 (2), pp. 31-37, 1982.

[2] G. Crawford. „Reverse logistics and the role of the steel can recycling institute". Annual conference, Council of Logistics Management, 1992.

[3] M.P. De Brito, R. Dekker. „A framework for reverse logistics" in Reverse logistics, Springer Berlin Heidelberg, 2004, pp. 3-27.

[4] S. Dowlatshahi "Developing a theory of reverse logistics”. Interfaces, 30 (3), pp. 143-155, 2000.

[5] M. Fleischmann, J.M. Bloemhof-Ruwaard, R. Dekker, E. Van der Laan, J.A. Van Nunen, L.N. Van Wassenhove. „Quantitative models for reverse logistics: A review". European journal of operational research, 103(1), pp. 1-17, 1997.

[6] A. Gandolfo, R. Sbrana. „Reverse Logistics and MarketDriven Management". Symphonya. Emerging Issues in Management, (2), pp. 28-40, 2008

\footnotetext{
Monika Kosacka-Olejnik

ORCID ID: 0000-0001-6950-2728

Poznan Univeristy of Technology, Faculty of Engineering Management Jacka Rychlewskiego 2, 60-969 Poznan, Poland e-mail: monika.kosacka@put.poznan.pl
}

\section{Karolina Werner-Lewandowska}

ORCID ID: 0000-0002-9549-4511

Poznan Univeristy of Technology, Faculty of Engineering Management Jacka Rychlewskiego 2, 60-969 Poznan, Poland e-mail: karolina.werner@put.poznan.pl
[7] K. Govindan, H. Soleimani, D. Kannan. „Reverse logistics and closed-loop supply chain: A comprehensive review to explore the future". European Journal of Operational Research, 240(3), pp. 603-626, 2015.

[8] [online] Available: http://www.reverselogisticstrends.com/reverse-logistics.php [May, 12, 2018].

[9] B. Kitchenham (2004, June). „Procedures for performing systematic reviews". Keele, UK, Keele University. [Online]. 33, pp. 1-26. Available: www.ifs.tuwien.ac.at/ weippl/systemicReviewsSoftwareEngineering.pdf [Jan. 13, 2018].

[10] H. J. Ko, G.W. Evans, G. W. „A genetic algorithm-based heuristic for the dynamic integrated forward/reverse logistics network for 3PLs". Computers \& Operations Research, 34(2), pp. 346-366, 2007.

[11] M. Kosacka-Olejnik, K. Werner-Lewandowska. „The Reverse Logistics Maturity Model: How to determine reverse logistics maturity profile: method proposal", presented at the $28^{\text {th }}$ International Conference on Flexible Automation \& Intelligent Manufacturing (FAIM2018), Columbus, USA, 2018.

[12] H. Min, H.J. Ko, C.S. Ko „A genetic algorithm approach to developing the multi-echelon reverse logistics network for product returns". Omega, 34(1), pp. 56-69, 2006.

[13] S. Pokharel, A. Mutha. „Perspectives in reverse logistics: a review". Resources, Conservation and Recycling, 53(4), pp. 175-182, 2009.

[14] V. Ravi, R. Shankar. „Analysis of interactions among the barriers of reverse logistics". Technological Forecasting and Social Change, 72(8), pp. 1011-1029, 2005.

[15] V. Ravi, R. Shankar, M.K. Tiwari. „Analyzing alternatives in reverse logistics for end-of-life computers: ANP and balanced scorecard approach". Computers \& industrial engineering, 48(2), pp. 327-356, 2005.

[16] D.S. Rogers, P. Tibben-Lembke, "Going Backwards: Reverse Logistics Trends and Practices", Reverse Logistics Executive Council University of Nevada Reno Center for Logistics Management, 1998.

[17] M.I.G. Salema, A.P. Barbosa-Povoa, A.Q. Novais. „An optimization model for the design of a capacitated multi-product reverse logistics network with uncertainty". European Journal of Operational Research, 179(3), pp. 1063-1077, 2007.

[18] S.K. Srivastava. "Network design for reverse logistics". Omega, 36(4), pp. 535-548, 2008.

[19] J.R. Stock. Reverse Logistics: White Paper. Oak Brook, IL: Council of Logistics Management, 1992.

[20] M. Thierry, M. Salomon, J. Van Nunen, L. Van Wassenhove. "Strategic issues in product recovery management". California management review, 37(2), pp. 114-136, 1995. 